\title{
Sustainable agricultural development: from sectoral to ecosystem approach
}

\author{
Andrey Misyura, and Svetlana Orekhova* \\ Ural State University of Economic, 620144, Ekaterinburg, Russian Federation
}

\begin{abstract}
The article is devoted to the study of the prospects for using the ecosystem approach in agriculture. The methodology of research is based on the concept of sustainable development, ecosystem theory and platform economy. Research methods and materials deal with economic and statistical analysis of the agricultural industry and related branches of agricultural engineering and the land market in Russia. The main idea of the article is the assumption that in order to ensure sustainable development, it is necessary to integrate the listed industries into a single ecosystem based on the same technological standards and digital platform solutions, with a unified coordination center. The main problem in the organization of the ecosystem in agriculture in Russia is the systemic dependence of the industry on institutional factors, primarily government subsidies and the lack of specific design solutions in the field of its sustainable development. The authors see the development of another hightech sector in the economy of the Russian Federation as a result of the organization of an ecosystem in agriculture.
\end{abstract}

\section{Introduction}

The concept of sustainable development, proposed in the early $80 \mathrm{~s}$ of the last century, today is recognized by countries as an imperative. [1,2,3] The most common approach to sustainable development is the study of macroeconomic trends associated with the analysis of global socio-economic phenomena and environmental problems that affect the processes of life of the whole society. At the same time, a number of researchers (for example, $[4,5]$ ) illustrates that adherence to the principles of sustainable development is becoming an increasing priority for individual companies as well.

Building a business model based on the principles of economy, social responsibility and environmental sustainability is especially important for organizations in the real sector of the economy [6,7]. On this background, the crisis caused by COVID-19 and price volatility in the oil market has led to a powerful technological shift in the activities of markets and individual firms. These changes suppose the introduction of new business standards and challenge the government to determine the vector of economic recovery.

Traditionally, practical approaches in such cases come down to support the affected industries and / or creating new innovative products that could become "drivers" of

\footnotetext{
* Corresponding author: bentarask@list.ru
} 
economic growth in the near future. The specificity of the application of the first approach makes it possible to stabilize the situation but does not allow creating a new source of economic growth. The second approach has the risk of obtaining a local effect from the introduction of innovations. At the same time, in practice, there are already business models that are innovations in themselves. Such business models most often involve the configuration of platform and other ecosystems.

The purpose of this study is to study the possibilities of the ecosystem business model in agriculture and related industries to ensure sustainable development of both this sector and the Russian economy as a whole.

The objectives of the study are to establish the principles of building an ecosystem approach, analyze the state of the agricultural market and related markets (primarily, the agricultural machinery market), identify opportunities and tools for their integration into a single ecosystem.

\section{Materials and Methods}

\subsection{Theoretical framework}

Ecosystems as special market patterns [8] are understood as "a process of continuous formal and informal agreements between autonomous agents, as a result of which rules are created. These rules are shared by all participants and bring them mutual benefits " $[9, \mathrm{p}$. 24].

Depending on the diversity and changes in the structure of participants [10], their density [11] and closeness of connection [12], different types of ecosystems are distinguished. Methods of measuring these ecosystems properties are based on the idea of their territorially local nature and natural analogues (biogeocenoses). A number of works, including $[13,14,15]$, focuses on platform ecosystems. Technology in such ecosystems is the main reason for the unification of participants and is understood as a set of technological standards.

Ecosystems involve cooperation, which leads to receiving relational rent through direct and indirect (cross) network effects. For high-tech business, which is the main unit of analysis in the concept of sustainable development and the "Industry 4.0" paradigm, R. Seiger et al. [16] distinguishes engineering coordination, which consists in using a consistent and uniform model of product production at all stages of development; and a unified environment for the exchange of information and resources.

The modularity of an ecosystem means that all participants in the ecosystem are autonomous, but unlike market relationships, they are difficult to replace, since each of them creates additional value for the client, as well as due to the problem of technological and institutional identity. Connections in ecosystems are not built hierarchically, but rather horizontally.

There is a stereotypical view that more high-tech industries should become a growth driver for supplying industries. However, we believe that agricultural enterprises can become a mediator (aggregator) of one of the ecosystems in Russia. Using the methods of economic and statistical analysis, the dynamics of indicators, the connectivity of the economic results of agriculture and related industries, we will assess the state and potential of ecosystem formation in agriculture of Russia. 


\subsection{Analysis of the state and development potential of the agricultural market and related industries in the Russian Federation}

According to the Report on the State and Use of Agricultural Lands in the Russian Federation, prepared by the Ministry of Agriculture of the Russian Federation in 2020, on January 1, 2019, the area of the land fund amounted to 1,712.5 million hectares, of which agricultural land occupied $22.3 \%$. The total area of agricultural land as part of agricultural land amounted to 197.7 million hectares, including the total area of arable land - 58.8\%, hayfields $-9.5 \%$. According to this indicator, the Russian Federation ranks 5-6 in the world. Rational and efficient use of agricultural land is an important factor in ensuring the food security of the Russian Federation. In this regard, the tasks aimed at identifying unused agricultural land, primarily agricultural land, and their involvement in agricultural turnover, are becoming priorities for the development of the country's agro-industrial complex. The area of unused agricultural land in the Russian Federation on 01.01.2019 accounts for $16.7 \%$ of the total area. In the structure of the identified unused arable land, it is advisable to single out arable land suitable for introduction into agricultural use, which does not require preliminary special cultural and technical measures. The total area of such arable land is 9.8 million hectares (almost 50\%).

The number of peasant and private farms in Russia on January 1, 2020 was 176.3 thousand units.

The main growth point of the agricultural sector in 2019 was crop production - the production of grain and oilseeds. According to Rosstat, the gross grain harvest amounted to 121.2 million tons - the second result in the history of modern Russia (the 2017 harvest remains a record - 130 million tons). Crop production in value terms amounted to 3.16 trillion. rubles, having increased over the year by $14.66 \%$.

Agricultural machine building (tractors, combine harvesters and harrows) is one of the key segments of the machine building complex with a share in the production of machines and equipment of $18.8 \%$, which has a double value for the Russian economy. Nevertheless, the contribution of domestic agricultural engineering enterprises to Russia's GDP today is only $0.13 \%$. The reasons for this are insufficient effective demand (the average purchase of agricultural machinery over the past 5 years was about 3 times lower than the market capacity) and virtually no export (3.9\% of the total output).

According to the "Strategy for the Development of Agricultural Engineering in Russia for the Period up to 2030", in order to renew the fleet of equipment in the country, taking into account the disposal of old machines, it is necessary to buy more than 50 thousand tractors for the amount of over 300 billion rubles annually. and more than 18 thousand combines with a total value of over 140 billion rubles. According to Rosstat, in October 2018, the average age of a tractor in the Russian fleet of agricultural machinery was 19 years.

\subsection{The role of the state in building an agricultural ecosystem}

The key problem of building a single ecosystem based on the dominant role of the agricultural market is still the subsidized nature of the development of the agro-industrial complex (AIC).

According to the «Agricultural Market Review», the main factor in increasing the competitiveness of the agro-industrial complex is government support. According to Rosstat, $75 \%$ of the profits of agribusiness companies over the past four years have been generated through subsidies received from the state. Subsidies remain one of the key factors in making investment decisions in the agro-industrial complex. 
The development of the export of agricultural machinery is one of the main priorities of the domestic agricultural machinery industry. In 2017, the Government of the Russian Federation adopted the "Strategy for the development of exports in the agricultural engineering industry for the period up to 2025". Russian agricultural products are now supplied to 160 countries, China remains the main buyer of Russian food products, having increased purchases in 2019 from $\$ 2.5$ billion to $\$ 3.1$ billion. To support the export of agricultural products, the government allocated 33.8 billion rubles for 2020 , that is, $12 \%$ of the total financing of the industry. In addition, exporters will be reimbursed for the costs incurred in the certification of agricultural products sent to foreign markets. Assistance will be provided to agricultural enterprises that grow and process soybeans and rapeseed.

Since April 2019, the Rosagroleasing program has been in effect, designed specifically to level the costs of agricultural enterprises in the current situation. It assumes a preferential rate of $3 \%$, a zero advance payment, an extension of the lease term and a deferred payment for one year.

Manufacturers such as Rostselmash, PTZ and KLAAS owe their financial results to the direct support of the Russian state. So, in accordance with the data of the Ministry of Agriculture of the Russian Federation, exactly three listed companies accounted for $70 \%$ of subsidies provided to agricultural machine builders under the RF Government Decree No. 1432 dated December 27, 2012. At the same time, there is a slowdown in the growth rate of export deliveries of agricultural machinery, which is associated with a reduction in the size of subsidies under the program to compensate the costs of transporting industrial products (from $25-27.5 \%$ to $11-13 \%$ of the cost of products).

\section{Results and Discussion}

The prospects of the agro-industrial complex are visible against the background of its stable growth in the conditions of the crisis. According to Rosstat, in 2020 export wheat prices increased by $\$ 14-20$ per ton, depending on the class.

The competitive advantage of the country's agriculture can be achieved by reducing the cost of growing and harvesting crops, increasing yields through the automation of these processes. First of all, automation is required in terms of planting, care and harvesting. To a lesser extent in storage, transportation and processing. The need for automation processes will contribute to the emergence of new domestic industries that can meet the growing demand through the creation of innovative solutions for the needs of agricultural producers. Enterprises of the military-industrial complex can act as "innovators" as they have high scientific potential and experience in the transfer of technological solutions to civilian developments.

Thus, the greatest role in the development of agriculture will be played by the accompanying high-tech areas of production, which, on the one hand, will increase the contribution of agriculture to GDP, on the other hand, will become an independent significant source of growth in the country's GDP. This is the development and production of modern high-tech agricultural machinery with robotization elements, integrated satellite geoinformation navigation and telecommunication services, integration and development of new generation software products and materials for remote sensing of the Earth and unmanned vehicles, construction of a modern agricultural infrastructure using control and management based on artificial intelligence and unmanned technologies, development of information infrastructure in rural areas, creation of technologies and decision support platforms for agricultural producers, etc.

At the same time, the analysis of strategic documents in the field of digitalization of the economy showed the presence of a number of problematic issues that impede the active process of introducing digital technologies in the agro-industrial complex. Among them: 
- a clear sequence of achieving the goals and objectives in the field of digitalization.

- the lack of a unified coordination center for authorities, business, science and public organizations for the tasks of digitalization of the agro-industrial complex.

- the lack of linking indicators of the efficiency of digitalization of the agro-industrial complex to the final benefit for the agricultural producer (increasing the profitability of the farm, reducing the cost of seeds and fertilizers, increasing yields, etc.).

- lack of a methodology for assessing the level of digitalization of agricultural enterprises.

\section{Conclusion}

Industries and firms as units of analysis are losing importance as technology evolves in the context of collaboration, resource sharing, and distributed manufacturing. [17, p.46]

Building an ecosystem in the field of agro-industrial complex implies the creation of a complex integrator of digital solutions, which, on the one hand, will offer the customer all the benefits he needs, taking into account the wishes and specifics of his activities, on the other hand, accumulates a wide range of cooperation enterprises for his requirements.

Thus, not digital products will begin to be sold, the effectiveness of which may be questioned by the consumer, but platform solutions for farmers' tasks: increasing labor productivity; profit growth; reducing crop loss.

To build an ecosystem, the following steps are seen as necessary:

1) Determine the complex of needs of agricultural producers - what tasks they want to solve using digital technologies;

2) Create a mechanism for selecting projects for the digitalization of the agro-industrial complex;

3) Determine the specific conditions and sources of projects funding;

4) Determine a single institute that will act as a project office for the implementation and support of projects aimed at digitalizing the agro-industrial complex.

5) Identify priority pilot markets (“demand points") for digital approbation.

The ecosystem approach, ultimately, will allow, in parallel with the raw materials economy, to create a sector that will not only become one of the world leaders in itself, but also act as an aggregator of high-tech solutions for its own needs, providing an innovative multiplier effect in the country's economy and, as a consequence its growth in the coming years.

\section{References}

1. M. Ghobakhloo, Journal of Cleaner Production, 252, (119869) (2020)

2. C. Kroll, A. Warchold, P. Pradhan, Palgrave Communications, 5(140) (2019)

3. R. Sanguino, A. Barroso, S. Fernández-Rodríguez, M.I. Sánchez-Hernández, Current trends in economy, sustainable development, and energy: a circular economy view (2020)

4. R. Steurer, M.E. Langer, A. Konrad, A. Martinuzzi, Journal of Business Ethics, 61(3), 263 (2005)

5. T. Dyllick, Z. Rost, Journal of Cleaner Production, 162, 346 (2017)

6. A. Houshyar, A. Hoshyar, R. Sulaiman, Journal of Applied Environmental and Biological Sciences, 4(4), 7 (2014)

7. H.S. Kristensen, M.A. Mosgaard, Journal of Cleaner Production, 243,(118531) (2020) 
8. J. F. Gomes., M. Iivari, M. Pikkarainen, P. Ahokangas, International Journal of Social Ecology and Sustainable Development, 9(3), 1 (2018)

9. A. M. Thomson, J. L. Perry,Public Administration Review, 66(S1), 20 (2006)

10. D. Stangler, J. Bell-Masterson, Measuring an entrepreneurial ecosystems, Kaufmann Foundation (2015)

11. Z. Acs, E. Stam, D. Audretsch, A. O’Connor, Small Business Economics, 49(1), 1 (2017)

12. J. Crespo, R. Suire, J. Vicente, Journal of Economic Geography,14(1), 199 (2014)

13. A. Gawer, M.A.Cusumano, MIT Sloan Management Review, 49(2), 28 (2008)

14. J. Wareham, P.B. Fox, J.L. Cano, Science, 25(4), 1195 (2014)

15. R. Seiger, C. Keller, F. Niebling, T. Schlegel, Journal of Computational Science, 10, 137 (2014)

16. S.V. Orekhova, Journal of Economic Regulation, 8(4), 6 (2017)

17. S.V. Orekhova, M.V. Evseeva, Journal of Institutional Studies, 12(4), 34 (2020) 